\title{
SORPTION OF NEPTUNIUM ON CLAYS
}

\author{
S. AKSOYOGLU, W. BURKART, W. GOERLICH
}

Paul Scherrer Institut, CH-5232, Villigen PSI. (Switzerland)

(Received May 24, 1990)

\begin{abstract}
Batch sorption experiments with ${ }^{237} \mathrm{~Np}$ using kaolinite and molasse clays were carried out under oxic conditions. The sorption kinetics and the effects of particle size of clay samples, concentration of neptunium in the solutions and the $\mathrm{pH}$ below and above the point of zero charge of the clays on the sorption coefficients were studied. The sorption coefficients of neptunium, on kaolinite were between 23 and $1100 \mathrm{ml} / \mathrm{g}$ at $\mathrm{pH} 1.5$ and 7.6 , respectively, whereas, sorption on the molasse clay was not affected significantly by $\mathrm{pH}\left(\mathrm{R}_{\mathrm{d}} \sim 600 \mathrm{ml} / \mathrm{g}\right)$.
\end{abstract}

\section{Introduction}

Neptunium is one of the most important elements from the safety point of view due to its hazardous nuclide ${ }^{237} \mathrm{~Np}$ with a half-life of $2.1 \cdot 10^{6}$ years. It exists in five oxidation states in aqueous solutions and the most stable species under oxidizing conditions is the pentavalent one $\left(\mathrm{NpO}_{2}^{+} \cdot \mathrm{aq}\right) \cdot{ }^{1}$ On the other hand, $\mathrm{Np}(\mathrm{IV})$ dominates under reducing conditions.

Sorption of neptunium was widely studied on different solids like basalt, bentonite and granitic rocks under oxic and anoxic conditions. ${ }^{2-4}$ This paper presents the results of batch sorption experiments with ${ }^{237} \mathrm{~Np}$ using two different types of clays under oxic conditions.

\section{Materials and methods}

Molasse clay used in the experiments was taken from the clay horizon of NorthEast Switzerland. It consisted of 65-70\% montmorillonite, 5-10\% illite and small amounts of quartz. Kaolinite test material from Zettlitz (Czechoslovakia) contained $90 \%$ kaolinite, $2-5 \%$ illite and $2-5 \%$ quartz. Both samples were separated into 2 particle size ranges as $5-10 \mu \mathrm{m}$ and $10-20 \mu \mathrm{m}$ by the Andreasen pipette method. ${ }^{5}$

The neptunium solutions were prepared by diluting a standard ${ }^{237} \mathrm{~Np}$ solution with Säckingen ground water. ${ }^{6}$ This water was strongly mineralized and had a $\mathrm{pH}$ of 8. The concentrations of $\mathrm{Np}$ in the solutions were between $10^{-6}$ and $10^{-9} \mathrm{M}$. The oxidation states of neptunium in the solutions were checked by thenoyltrifluor- 
acetone (TTA) extraction method. ${ }^{7}$ The $\mathrm{pH}$ of the solutions were adjusted by $\mathrm{HNO}_{3}$. Solid/liquid ratio was kept constant for all the experiments as $1 / 100$.

The experiments were carried out in polyallomer centrifuge tubes. Before sorption, the clay samples were equilibrated with groundwater for four days. The samples were shaken at $200 \mathrm{rpm}$ and phase separation was performed by centrifuging at $10000 \mathrm{rpm}$. The $\alpha$-activity of ${ }^{237} \mathrm{~Np}$ was measured by a surface barrier silicon detector. Desorption tests were performed after the sorption procedures, by replacing the solutions with the groundwater.

\section{Results and discussion}

The extraction with TTA showed that about $98 \%$ of neptunium in the solutions was in the $5+$ oxidation state. The solubility calculations with the geochemical code PHREEQE ${ }^{8}$ indicated that the precipitation of $\mathrm{NpO}_{2}$ was likely at the highest $\mathrm{Np}$ concentration $\left(10^{-6} \mathrm{M}\right)$. The speciation calculations with the same code suggested that the main species in the neutral solutions were $\mathrm{NpO}_{2}^{+}$and $\mathrm{NpO}_{2} \mathrm{CO}_{3}^{-}$, whereas, in the solution with low $\mathrm{pH}$, the dominant species was $\mathrm{NpO}_{2}^{+}$.

The isoelectric points, the $\mathrm{pH}$ at which the net charge on the surface is zero, is around 3.5 and less than 2.5 for kaolinite and montmorillonite type of clays respectively. ${ }^{9-11}$ At $\mathrm{pH} 1.5$, therefore, the surface of both kaolinite and molasse clays are supposed to be positively charged.

The change in sorption coefficients $\left(R_{d}\right)$ with time for both of the clays $(5-10 \mu \mathrm{m})$ at $\mathrm{pH} 1.5$ and $\mathrm{pH} 7.6$ is shown in Fig. 1. It is seen that the sorption of neptunium on molasse clay is nearly $\mathrm{pH}$ independent (except the kinetics of sorption), whereas

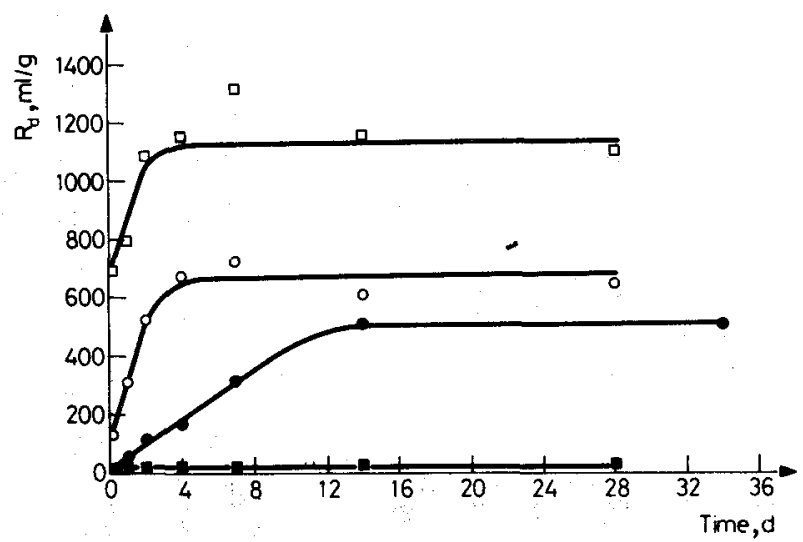

Fig. 1. Change of $\mathbf{R}_{\mathbf{d}}$ of $\mathrm{Np}$ with time for kaolinite and molasse clays: $\bullet$ molasse $\mathrm{pH} 1.5$, $\circ$ molasse $\mathrm{pH} 7.6$, - kaolinite $\mathrm{pH} 1.5$, 口 kaolinite $\mathrm{pH} 7.6$ 
sorption on kaolinite displays a strong dependence on $\mathrm{pH}$. The explanation of this fact can be the tightly bound layers in kaolinite, therefore, the reactions occur mainly on the surfaces of the outer layers which are positively charged at low $\mathrm{pH}$. On the other hand, since the interlayers in the expandable smectite type clays are also available for sorption, the effect of surface charge is less than in the case of kaolinite. Presumably, diffusion into the interlayers caused the slow kinetics at low $\mathrm{pH}$.

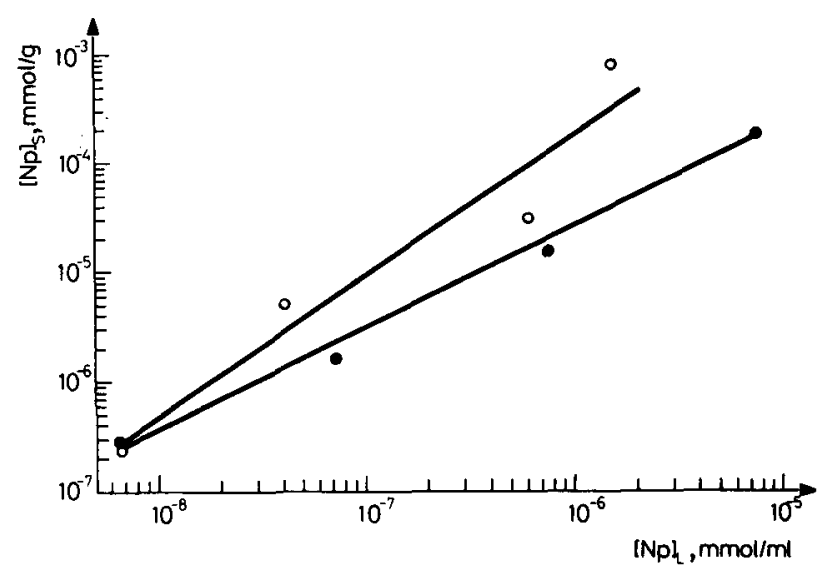

Fig. 2. Freundich isotherms for Np sorption on kaolinite and molasse clays: • kaolinite, o molasse

The sorption coefficients of neptunium on molasse clay were measured as 600 and $450 \mathrm{ml} / \mathrm{g}$ for the particle sizes 5-10 and 10-20 $\mu \mathrm{m}$, respectively. On the other hand, on kaolinite clay, $R_{d}$ were 1100 and $550 \mathrm{ml} / \mathrm{g}$ respectively, for the same size ranges as above. The higher $R_{d}$ for smaller particle sizes observed especially in the case of kaolinite clay suggests also, as $\mathrm{pH}$ dependency, a surface adsorption on this clay. The desorption tests suggested a clear irreversibility for both clays.

The experimental data was fitted to Freundlich isotherm. ${ }^{12}$ In Fig. 2, isotherms for both of the clays with 5-10 $\mu \mathrm{m}$ particle sizes are shown. The Freundlich constants are given in Table 1.

Table 1 .

Freundlich constants for sorption

\begin{tabular}{lccc}
\multicolumn{4}{c}{ of $\mathrm{Np}$ (equation: $\left.[\mathrm{Np}]_{\text {solid }}=\mathrm{K} \cdot[\mathrm{Np}]_{\text {liquid }}^{\mathrm{N}}\right)$} \\
\hline Clay & $\mathrm{K}$ & $\mathrm{N}$ & $\mathrm{r}$ \\
\hline Kaolinite & 6.92 & 0.91 & 0.996 \\
Molasse & 15488 & 1.32 & 0.965 \\
\hline
\end{tabular}




\section{S. AKSOYOGLU et al.: SORPTION OF NEPTUNIUM ON CLAYS}

Isotherm for $\mathrm{Np}$ sorption on molasse clay suggests some precipitation at $\mathrm{Np}$ concentrations higher than $10^{-6} \mathrm{M}(\mathrm{N}>1$ is also an indication of precipitation). On the other hand, the isotherm for $\mathrm{Np}$ sorption on kaolinite is nearly linear.

One of the authors (SA) would like to thank IAEA for financial support during this work.

\section{References}

1. S. AHRLAND, J. O. LILJENZIN, J. RYDBERG, Solution Chemistry, Vol. S, Actinides, J. C. Bailer, New York, 1973.

2. B. ALLARD, H. KIPATSI, J. RYDBERG, KBS Technical Report, 55 (1977).

3. G. BIDOGLIO, A. DE PLANO, Nulc. Technol., 74 (1986) 307.

4. B. TORSTENFELT, Radiochim. Acta, 39 (1986) 105.

5. B. A. WILLS, Mineral Processing Technology, Pergamon Press, 1979.

6. S. AKSOYOGLU, J. Radioanal. Nucl. Chem., 134 (1989) 393.

7. P. A. BERTRAND, G. R. CHOPPIN, Radiochim. Acta, 31 (1982) 135.

8. D. L. PAR KHURST, D. C. THORSTENSON, L. N. PLUMMER, NTIS Techn. Report PB 81$167801,1980$.

9. G. A. PARKS, Chem. Rev., 65 (1965) 177.

10. J. O. LECKIE, R. O. JAMES, Aqueous Environmental Chemistry of Metals, A. J. RUBIN (Ed.), Ann Arbor Science Publishers, Ann Arbor, Mich., 1974, p. 1.

11. R. O. JAMES, M. G. MacNAUGHTON, Geochim. Cosmochim. Acta, 41 (1977) 1549.

12. H. FREUNDLICH, Colloid and Capillary Chemistry, Methuen, London, 1926. 